\title{
O DIREITO À EDUCAÇÃO NO CONTEXTO DA PANDEMIA (COVID-19) NO BRASIL: PROJETOS DE FORMAÇÃO EM DISPUTA
}

\author{
Vanessa Campos de Lara Jakimiu ${ }^{\mathrm{i}}$
}

RESUMO: O presente estudo tem como objetivo apresentar um quadro teórico acerca dos desdobramentos da pandemia (COVID-19) na garantia do direito à educação no Brasil. Metodologicamente adota-se os moldes da pesquisa teórica bibliográfica de cunho qualitativo fundamentando-se na abordagem dialética. O estudo está amparado em documentos legais emitidos para normatizar a educação em tempos de pandemia e em autores da bibliografia especializada com especial destaque para Adorno (1993), Freire (1998), Giroux (1986) e Krenak (2019, 2020, 2020a). Do estudo empreendido, é possível constatar que as iniciativas governamentais apresentadas diante do contexto de pandemia não só não avançam na garantia do direito à educação, como fazem o seu contrário, retrocedem.

Palavras-chave: Direito à Educação; Pandemia (COVID-19); Projetos de formação em disputa.

\section{THE RIGHT TO EDUCATION IN THE CONTEXT OF PANDEMIA (COVID-19) IN BRAZIL: TRAINING PROJECTS IN DISPUTE}

\begin{abstract}
This study aims to present a theoretical framework about the consequences of the pandemic (COVID-19) to guarantee the right to education in Brazil. Methodologically, we adopt the molds of bibliographic theoretical research of a qualitative nature, based on the dialectical approach. The study is supported in legal documents issued to standardize education in times of pandemic and in authors of specialized bibliography with special emphasis on Adorno (1993), Freire (1998), Giroux (1986) and Krenak $(2019,2020,2020 a)$. From the study undertaken, it is possible to see that the government initiatives presented in the context of the pandemic context not only do not advance in guaranteeing the right to education, but they do the opposite, they fall back.
\end{abstract}

Keywords: Right to Education; Pandemic (COVID-19); Training projects in dispute.

\section{INTRODUÇÃO}

Devido à pandemia provocada pela doença COVID-19 estudantes do mundo tiveram suas aulas substituídas pelo ensino remoto emergencial. De acordo com a diretora da Organização das Nações Unidas para a Educação, a Ciência e a Cultura (UNESCO), Audrey Azoulay, esta condição está impondo desafios para ser capaz de "[...] proporcionar um aprendizado ininterrupto a todas as crianças e jovens de maneira equitativa”. (AZOULAY..., 2020, não paginado). 
No Brasil este desafio torna-se ainda mais complexo uma vez que a educação enquanto direito social se funda historicamente a partir da negação do direito e profundamente marcado pelas desigualdades sociais. Neste sentido, o presente estudo tem como objetivo apresentar um quadro teórico acerca dos desdobramentos para a garantia do direito à educação no Brasil no contexto da pandemia (COVID-19).

Metodologicamente o estudo adota os moldes da pesquisa teórico bibliográfica de cunho qualitativo fundamentando-se na abordagem dialética a qual abrange "[...] o sistema de relações que constrói, o modo de conhecimento exterior ao sujeito, mas também as representações sociais que traduzem o mundo dos significados.” (MINAYO, 2001, p. 24). A abordagem dialética:

\footnotetext{
Busca encontrar, na parte, a compreensão e a relação com o todo; e a interioridade e a exterioridade como constitutivas dos fenômenos. Desta forma, considera que o fenômeno ou processo social tem que ser entendido nas suas determinações e transformações dadas pelos sujeitos. Compreende uma relação intrínseca de oposição e complementaridade entre o mundo natural e social, entre o pensamento e a base material. Advoga também a necessidade de se trabalhar com a complexidade, com a especificidade e com as diferenciações que os problemas e/ou "objetos sociais" apresentam. (MINAYO, 2001, p. $24-25)$.
}

Quanto à estrutura organizativa, inicialmente o estudo apresenta uma discussão acerca das ações governamentais implementadas no contexto de pandemia para a organização da educação brasileira. Em seguida, problematiza as implicações destas ações para o campo das políticas educacionais evidenciando projetos de formação em disputa. Por fim, o estudo apresenta teorizações no sentido de evidenciar a necessária (res)significação da sociedade e da educação tendo em vista a superação dos desafios impostos e/ou já existentes e reforçados pelo contexto de pandemia.

\section{AS AÇÕES DO GOVERNO FEDERAL PARA A EDUCAÇÃO BRASILEIRA NO CONTEXTO DE PANDEMIA: IMPLICAÇÕES NO CAMPO DAS POLÍTICAS EDUCACIONAIS}

No início do mês de março do ano de 2020, seguindo as orientações da Organização Mundial da Saúde (OMS), o Ministério da Saúde brasileiro, como forma de enfrentamento da pandemia provocada pela COVID-19, declarou a necessidade de, dentre outras medidas, implementar o distanciamento social (seletivo e ampliado) ou o bloqueio total (lockdown) a depender da situação epidemiológica apresentada. (BRASIL, 2020). 
Diante deste cenário, a primeira iniciativa normativa para a educação por parte do Governo Federal foi a publicação da Portaria 343/2020 no dia 17 de março. A referida portaria, autoriza em caráter excepcional, a substituição das disciplinas presenciais por aulas que utilizem meios e tecnologias das disciplinas presenciais no âmbito do Ensino Superior. De acordo com a referida Portaria e seu artigo $1^{\circ}$, o Ministro da Educação autoriza:

[...] em caráter excepcional, a substituição das disciplinas presenciais, em andamento, por aulas que utilizem meios e tecnologias de informação e comunicação, nos limites estabelecidos pela legislação em vigor, por instituição de educação superior integrante do sistema federal de ensino, de que trata 0 art. $2^{\circ}$ do Decreto $\mathrm{n}^{\circ} \mathbf{9 . 2 3 5}$, de 15 de dezembro de 2017. $\S 1^{\circ} \mathrm{O}$ período de autorização de que trata o caput será de até trinta dias, prorrogáveis, a depender de orientação do Ministério da Saúde e dos órgãos de saúde estaduais, municipais e distrital. § $2^{\circ}$ Será de responsabilidade das instituições a definição das disciplinas que poderão ser substituídas, a disponibilização de ferramentas aos alunos que permitam o acompanhamento dos conteúdos ofertados bem como a realização de avaliações durante o período da autorização de que trata o caput. $\S 3^{\circ}$ Fica vedada a aplicação da substituição de que trata o caput aos cursos de Medicina bem como às práticas profissionais de estágios e de laboratório dos demais cursos. $\S 4^{\circ}$ As instituições que optarem pela substituição de aulas deverão comunicar ao Ministério da Educação tal providência no período de até quinze dias. (BRASIL, 2020a, não paginado, grifo nosso).

O Parecer prevê também em seu artigo $2^{\circ}$ a suspensão das atividades acadêmicas presenciais desde que sejam respostas integralmente posteriormente:

Art. $2^{\circ}$ Alternativamente à autorização de que trata o art. $1^{\circ}$, as instituições de educação superior poderão suspender as atividades acadêmicas presenciais pelo mesmo prazo. $\S 1^{\circ}$ As atividades acadêmicas suspensas deverão ser integralmente repostas para fins de cumprimento dos dias letivos e horas-aulas estabelecidos na legislação em vigor. $\S$ $2^{\circ}$ As instituições poderão, ainda, alterar o calendário de férias, desde que cumpram os dias letivos e horas-aula estabelecidos na legislação em vigor. (BRASIL, 2020a, não paginado, grifo nosso).

E já no dia 19 de março o governo publica a Portaria 345/2020 que altera a Portaria 343/2020 para estabelecer a vedação de substituição das disciplinas presenciais por aulas que utilizem meios e tecnologias de informação e comunicação quando se tratar de práticas profissionais de estágios e de laboratório:

Art. $1^{\circ}$ A Portaria MEC $n^{\circ} 343$, de 17 de março de 2020, passa a vigorar com as seguintes alterações: "Art. $1^{\circ}$ Fica autorizada, em caráter excepcional, a substituição das disciplinas presenciais, em andamento, por aulas que utilizem meios e tecnologias de informação e comunicação, por instituição de educação superior integrante do sistema federal de ensino, de que trata $\mathrm{o}$ art. $2^{\circ}$ do Decreto $\mathrm{n}^{\mathrm{o}}$ 9.235, de 15 de dezembro de 2017.

$\S 3^{\circ}$ Fica vedada a aplicação da substituição de que trata o caput às práticas profissionais de estágios e de laboratório. $\S 4^{\circ}$ Especificamente para o curso de 
Medicina, fica autorizada a substituição de que trata o caput apenas às disciplinas teóricas-cognitivas do primeiro ao quarto ano do curso. $\S 5^{\circ}$ As instituições deverão comunicar ao Ministério da Educação a opção pela substituição de aulas, mediante ofício, em até quinze dias." (NR) (BRASIL, 2020b, não paginado, grifo nosso).

Após a publicação das portarias, muitas universidades se mobilizaram para implementar a substituição das disciplinas presenciais por aulas que utilizem meios e tecnologias de informação e comunicação, no entanto, já nas primeiras incursões foram encontradas fragilidades estruturais, pedagógicas e humanas que impediram a continuidade das atividades acadêmicas.

Do ponto de vista estrutural a referida implementação acabou por evidenciar as desigualdades sociais que marcam nosso país, revelando que nem todos os acadêmicos do Ensino Superior possuem recursos tecnológicos e acesso à internet. Fator que fez com que a maioria das universidades federais deliberassem pela suspensão do calendário acadêmico. (MEC, 2020a). ${ }^{\text {ii }}$

Em nota justificando a suspensão das atividades acadêmicas, o Reitor Alfredo Macedo Gomes da Universidade Federal do Pernambuco (UFPE) se fundamenta na Lei 12.711/2012 (BRASIL, 2012) a qual estabelece a destinação de $50 \%$ das vagas dos cursos de graduação para o ingresso de estudantes oriundos de famílias com renda igual ou inferior a 1,5 salário-mínimo per capita. No entendimento do mesmo a implementação das orientações normativas do MEC não garantem o princípio da isonomia:

São evidentes as dificuldades que essa parcela do corpo discente encontra para acesso a "hardware" (computadores, "notebooks", "tablets" e similares) adequado para atividades de ensino a distância, bem como ao acesso - de boa qualidade - à rede mundial de computadores. Aos alunos e alunas que não disponham dessa estrutura e conexão, restaria, portanto, a buscar apoio junto a familiares e colegas, ou mesmo se dirigir a "lan houses" e estabelecimentos similares, o que violaria as regras de isolamento social determinadas pelas autoridades públicas, além de expô-los a desnecessário risco, na contramão das medidas adotadas para o combate à crise causada pela Covid-19. A UFPE busca, permanentemente, garantir isonomia nas condições de permanência dos estudantes durante as aulas e demais atividades formativas. Tratar os estudantes com isonomia significa pensar em caminhos para atender a cada um deles na sua especificidade durante o processo de ensino, aprendizagem e avaliação. (GOMES, 2020, não paginado).

A realidade vivenciada pela UFPE é a mesma de todas as demais universidades públicas já que a lei mencionada pelo Reitor trata-se de uma lei federal aplicável à todas. Assim sendo, as desigualdades sociais estão presentes de forma maior ou menor em todas as universidades dos estados brasileiros.

Do ponto de vista pedagógico (e estrutural) a dificuldade do acesso e utilização dos recursos tecnológicos, tanto pelos professores quanto pelos acadêmicos, torna-se um desafio, já que não há instituída uma cultura de utilização das tecnologias como elemento formativo na maioria das universidades que adotam aulas presenciais no Brasil. 
Neste sentido, de acordo com o Professor Helder Gusso, da Universidade Federal de Santa Catarina (UFSC), especialista em tecnologias educacionais, o que ocorre no Brasil é a implementação de um "ensino remoto emergencial" uma vez que os encaminhamentos adotados no Brasil (e em várias partes do mundo) não se constituem como Educação à Distância (EAD), sobretudo, devido “[...] a ausência de material programado para essa modalidade”. (GUSSO, 2020, não paginado).

A não garantia da privacidade na utilização das plataformas digitais é outro fator que induziu algumas universidades brasileiras a não adotarem o ensino remoto emergencial. (BANDEIRA; PASTI, 2020).

O próprio Zoom Meeting, aplicativo que estava sendo utilizado como mecanismo de comunicação por acadêmicos, professores e gestores para a realização de aulas e reuniões foi bloqueado pela ANVISA devido à questões frágeis de segurança. (ANVISA, 2020).

Lopes (2020) discutindo sobre a implementação de aplicativos para rastrear a disseminação do COVID-19 por meio do acesso a dados coletados especialmente de celulares de centenas de milhões de cidadãos adotados pelos países coloca a necessidade de uma discussão aprofundada sobre privacidade sem polarizar a questão:

[...] a tecnologia pode ser aliada no combate a essa pandemia. Trata-se de uma grande vantagem em relação a outras pandemias que a humanidade sofreu em outros momentos. Porém, é importante que a discussão não se restrinja a uma dicotomia simplista entre a saúde e a vida da população, de um lado, e a proteção de dados pessoais e a privacidade, de outro. (LOPES, 2020, não paginado).

Do ponto de vista humano, a implementação do ensino remoto emergencial se torna fragilizado, uma vez que a permanência das pessoas em casa provocada pelas medidas de distanciamento social, resulta em mudanças nas rotinas interferindo nas múltiplas realidades sociais.

Mesmo diante do posicionamento da maioria das universidades deliberando pela suspensão dos calendários acadêmicos, no dia 1 de abril, o Poder Executivo apresenta a Medida Provisória (MPV) 934 que emite a primeira normatização voltada também para a Educação Básica.

De acordo com a MPV 934/2020 as instituições de Educação Básica, em caráter excepcional, ficam dispensadas do cumprimento dos 200 dias letivos desde que cumprida a carga horária mínima anual de 800 horas prevista pela Lei de Diretrizes e Bases da Educação Nacional (LDBEN) 9.394/96.

A normatização também prevê a flexibilidade quanto à organização do calendário acadêmico no Ensino Superior:

Art. $2^{\circ}$ As instituições de educação superior ficam dispensadas, em caráter excepcional, da obrigatoriedade de observância ao mínimo de dias de efetivo trabalho acadêmico, nos termos do disposto no caput e no $\S 3$ o do art. 47 da Lei $\mathrm{n}^{\circ}$ 9.394, de 1996, para o ano letivo afetado pelas medidas para enfrentamento da situação de emergência de saúde 
pública de que trata a Lei $\mathrm{n}^{\circ} 13.979$, de 2020, observadas as normas a serem editadas pelos respectivos sistemas de ensino. Parágrafo único. Na hipótese de que trata o caput, a instituição de educação superior poderá abreviar a duração dos cursos de Medicina, Farmácia, Enfermagem e Fisioterapia, desde que o aluno, observadas as regras a serem editadas pelo respectivo sistema de ensino, cumpra, no mínimo: I - setenta e cinco por cento da carga horária do internato do curso de medicina; ou II - setenta e cinco por cento da carga horária do estágio curricular obrigatório dos cursos de enfermagem, farmácia e fisioterapia. (MPV 934, 2020, não paginado).

Do ponto de vista da organização do trabalho pedagógico, em especial na Educação Básica, a MPV 934/2020 acaba por retroceder em uma conjuntura já frágil, já que ao manter a carga horária de 800 horas simplesmente faz com que essas horas sejam divididas pelos dias restantes na retomada das aulas presenciais após o contexto de pandemia. Na prática se em 200 dias letivos os professores trabalham 4 horas com seus alunos, em 100 dias letivos, por exemplo, teriam, a partir da MPV, que trabalhar 8 horas para "cumprir" as horas previstas em lei e/ou desdobrar estas horas em finais de semana/feriados/férias etc. Na prática tal encaminhamento é simplesmente insustentável uma vez que desconsidera a realidade da educação brasileira e as trajetórias docentes que na maioria dos casos são constituídas de até três períodos distintos.

A insustentação prática desta normativa e o receio de assumir a responsabilidade por uma possível reposição induz os governos estaduais e municipais a adotarem também o ensino remoto emergencial.

Neste sentido, os professores da Educação Básica que até então estavam em distanciamento social, e na maioria dos casos, tendo seus dias de férias escolares descontados, são conclamados, a adotarem práticas escolares não presenciais: 
Figura 1 - Situação das práticas escolares à distância em 06 de abril de 2020

\section{Situação do ensino à distância \\ Redes estaduais de educação buscam soluções para periodo de quarentena}

Contarão com ensino não presencial

Férias antecipadas enquanto se planeja ensino não presencial

Aulas suspensas sem ensino não presencial

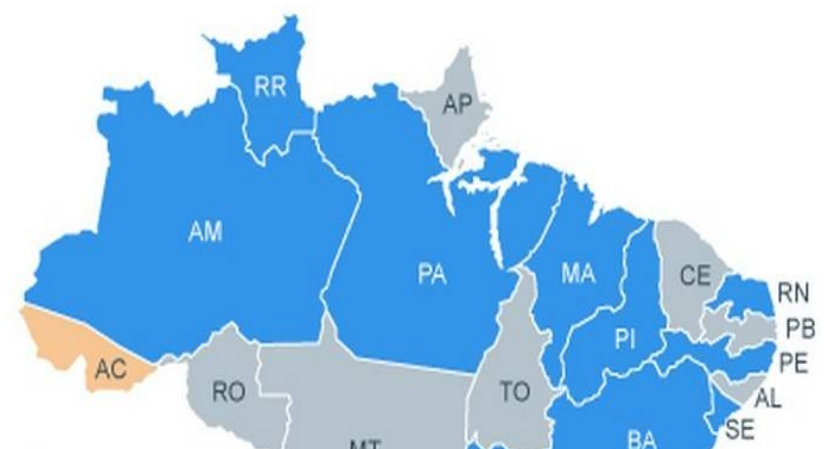

MT BA ES

\section{RS}

Fonte: Secretarias estaduais de educação

Fonte: Alfano e Souza, (2020).

No dia 28 de abril, o Conselho Nacional de Educação (CNE) aprova por unanimidade o Parecer CNE/CP 5/2020 prevendo orientações para a "reorganização do calendário escolar e da possibilidade de cômputo de atividades não presenciais para fins de cumprimento da carga horária mínima anual, em razão da Pandemia da COVID-19” (BRASIL, 2020c) e no dia 31 de março de 2020, um dia antes da publicação da MPV 934/2020, que trata apenas do cumprimento do calendário letivo e no caso da Educação Básica, das 800 horas anuais, o Conselho Nacional de Educação (CNE) expede nota informativa (CNE, 2020) explicando que a LDBEN 9.394/96 autoriza, em situações emergenciais, as atividades a distância no Ensino Fundamental, no Ensino Médio, na Educação Profissional Técnica de Nível Médio, na Educação de Jovens e Adultos e na Educação Especial conforme artigos $32 \S^{\circ}$ e $36 \S 11^{\circ}$ e que estas atividades podem ser validadas como "conteúdo acadêmico aplicado" desde que autorizado pelo estado ou município. (CNE, 2020, não paginado).

O CNE em nota informativa adverte acerca da qualidade das atividades a distância prevendo o "acompanhamento, avaliações e a participação correta dos alunos." Além disso, adverte que "as autoridades devem garantir o acesso de todos estudantes ao aprendizado" e que a escolas devem implementar metodologias próprias e mecanismos próprios "de fornecimento de conteúdo e acompanhamento avaliativo e da participação efetiva dos estudantes." (CNE, 2020, não paginado, grifo nosso). 
O CNE, tanto no texto do parecer quanto no texto da nota informativa, basicamente induz as instituições de ensino a adotarem as "atividades não presenciais" e explicita em sua nota informativa que “àquelas que não optarem por esta modalidade deverão repor os conteúdos e os dias letivos.” (CNE, 2020, não paginado, grifo nosso).

Tal iniciativa não só desconsidera o percurso percorrido pelas Universidades como também evidencia fragilidades estruturais, tecnológicas, pedagógicas e humanas próprias.

A implementação do ensino remoto emergencial na Educação Básica tem como primeiro entrave as desigualdades sociais e educacionais da realidade brasileira, na qual sequer estão supridas as demandas tecnológicas nos próprios sistemas de ensino.

De acordo com dados do Censo Escolar de 2019, embora o Ensino Fundamental possua o maior número de escolas e de matrículas ${ }^{\mathrm{iii}}$ é a etapa que dispõe de menos recursos tecnológicos. Com relação específica ao acesso à internet pelos estudantes na rede de ensino fundamental os dados revelam que a acessibilidade é de $83,0 \%$ na rede federal, $57,2 \%$ na rede estadual, $21,1 \%$ na rede municipal e $44,0 \%$ na rede privada. (CENSO..., 2019).

O cenário de desigualdade social, neste sentido, em tese, já seria suficiente para a não implementação do ensino remoto emergencial uma vez que deixa-se de cumprir a clara orientação do CNE no que tange ao atendimento efetivo à todos os estudantes.

Ainda que algumas iniciativas possam ser tomadas no sentido da garantia do acesso, como por exemplo, a utilização de redes de televisão e/ou rádio para promover as atividades não presenciais, isso não significa, a garantia das demais orientações do CNE nas questões específicas de cunho pedagógico como a garantia da qualidade e o acompanhamento avaliativo.

Além disso a implementação do ensino remoto emergencial na Educação Básica desconsidera os níveis de aprendizado em que se encontram os estudantes e as possíveis dificuldades que os mesmos podem ter para a realização das tarefas escolares, tanto com relação ao conhecimento específico propriamente dito, quanto com relação às orientações dos professores sobre como fazê-las.

A implementação do ensino remoto emergencial na Educação Básica desconsidera que no ambiente familiar os responsáveis pelas crianças podem apresentar dificuldades de acompanhá-las e orientá-las nas tarefas escolares uma vez que, em casa ou não, muitos continuam mantendo uma rotina exaustiva. Além disso, desconsidera também que as novas rotinas impostas pela permanência em distanciamento social interferem diretamente nos momentos de estudo e que em algumas realidades, estes momentos não poderão ocorrer devido às consequências econômicas, sociais e/ou de saúde provocadas pela pandemia (COVID-19).

Apesar de todos estes aspectos e outros apresentados pela cultura escolar consolidada, a partir da experiência prévia das demais etapas de ensino, algumas instituições da Educação Infantil estão 
implementando práticas educativas não presenciais, desconsiderando não só os preceitos previstos pela LDBEN 9.394/96 (BRASIL, 1996) e pelas Diretrizes Curriculares Nacionais para a Educação Infantil (DCNEI), (BRASIL, 2010), no que tange à especificidade da educação a ser ofertada para bebês e crianças, mas também as próprias normatizações emitidas pela MPV 934/2020 e pelas orientações emitidas pelo $\mathrm{CNE}$, as quais não autorizam qualquer iniciativa de cunho educacional não presencial para a etapa da educação infantil.

Não obstante o cenário apresentado, o Brasil ao manter os calendários escolares, ainda se depara com a manutenção de avaliações em larga escala, as quais no entendimento de Freitas (2020, não paginado), devem ser suspensas "[...] levando em conta os danos emocionais que a magnitude da pandemia está causando". Para o autor, o momento não é de "meritocracia" e "performatividade" e sim de solidariedade e acolhimento.

\section{O CONTEXTO EDUCACIONAL BRASILEIRO E OS PROJETOS FORMATIVOS EM DISPUTA NO CENÁRIO SUSCITADO PELO ENSINO REMOTO EMERGENCIAL EM TEMPOS DE PANDEMIA (COVID-19)}

No campo educacional as normatizações governamentais para orientar a educação brasileira nestes tempos de pandemia (COVID-19) evidenciam projetos de formação em disputa.

A primeira questão a ser considerada é a concepção restrita de educação apresentada pelos documentos normativos, tanto para Educação Básica quanto para o Ensino Superior, orientadas a partir de uma perspectiva conteudista.

Esta concepção remonta ao século XIX e está profundamente arraigada com os fundamentos e práticas da tendência liberal tradicional e tem como fundamento a manutenção da ordem vigente. Nesta, o professor é o transmissor do conteúdo, a aprendizagem é passiva e mecânica e o estudante é um mero receptor. (LIBÂNEO, 2011).

Tal concepção não dialoga com as perspectivas formativas em vigência previstas nas normatizações curriculares e preconizadas nas Diretrizes Curriculares Nacionais para a Educação Básica (DCNEB), (BRASIL, 2013), que tomam como referente o desenvolvimento integral, ou seja, a atribuição da escola é mais do que transmitir conteúdo.

Do ponto de vista da garantia do direito à educação a escola se ocupa da garantia da construção e da democratização do conhecimento (cultural, social, político, artístico, científico etc) acumulado historicamente: 
Uma contribuição inegável da escola é a possibilidade acumular conhecimentos sociais e historicamente produzidos pela humanidade, ou seja, é por causa da existência da escola que a sociedade evolui, cria e recria. Caso contrário, toda nova sociedade teria de reconstituir o passado para entender a ação dos indivíduos no tempo. A escola, portanto, além da preservação da memória, possui um caráter epistemológico e é responsável pela investigação e produção de conhecimento. (JAKIMIU, 2016, p. 313).

Além disso, como fundamento do desenvolvimento integral a escola também promove a socialização que é um dos aspectos formativos mais importantes e que está intrinsecamente ligado com a construção de conhecimentos. É na escola que crianças e jovens fortalecem a noção de identidade e coletividade e interagem com os pares criando e compartilhando culturas.

Além disso, a escola garante mecanismos de acesso à outros direitos sociais, especialmente àqueles relacionado à saúde e à alimentação, a maioria implementados por meio do Programa Nacional de Alimentação Escolar (PNAE) e por meio de ações intersetoriais entre o Ministério da Educação e o Ministério da Saúde, como por exemplo, o Programa Saúde Escolar (PSE). (MEC, 2020).

Em um país como o Brasil, profundamente marcado pelas desigualdades sociais é mais do que significativo, reconhecer a escola como um espaço de direitos. Direito à educação, direito à socialização, direito à alimentação, direito à saúde, direitos que historicamente foram negados e/ou restritos à uma determinada parcela da sociedade.

No sentido de promover uma reparação histórica, a escola enquanto espaço epistemológico, precisa garantir não somente o "conhecimento poderoso"iv no sentido atribuído por Young (2007) como também precisa ser justa de modo a garantir a igualdade de oportunidade para o acesso a bens escolares fundamentais. (DUBET, 2004)

A escola, sob esta perspectiva torna-se, portanto, como um potente instrumento para a redução das desigualdades sociais:

Figura 2 - A escola enquanto instrumento de redução das desigualdades sociais 


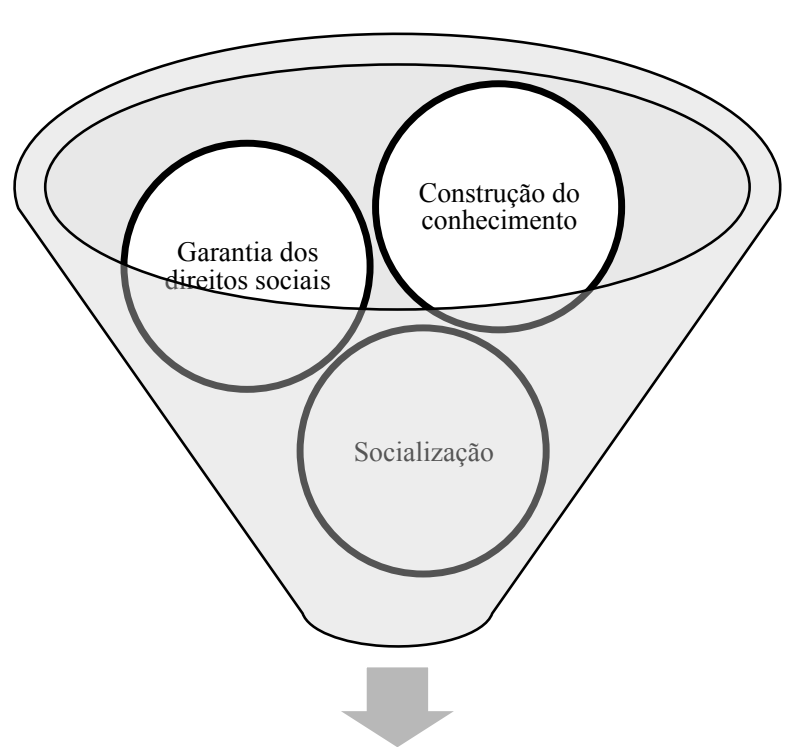

Redução das desigualdades sociais

Fonte: A autora, (2020).

A mesma reflexão se aplica ao Ensino Superior, ou seja, não é possível limitar às atividades das instituições de Ensino Superior, fundamentadas constitucionalmente, no preceito da indissociabilidade entre ensino, pesquisa e extensão, à simples repasse de conteúdos à distância. (BRASIL, 1988).

Cabe à universidade enquanto espaço epistemológico, em especial, neste contexto histórico, olhar criticamente esta realidade produzindo conhecimento. A universidade se constitui como lócus de produção de conhecimento ampliando as formas de viver em sociedade.

A concepção conteudista da educação a partir da adoção do ensino remoto emergencial tem, inclusive, implicações políticas uma vez que evidencia projetos de formação em disputa.

Em um país com profundas desigualdades sociais e educacionais e com aproximadamente 1,9 milhões crianças e jovens fora da escolav ${ }^{\mathrm{v}}$ (PNAD, 2017) implementar o ensino remoto emergencial de forma acrítica vai justamente na direção da precarização e substituição permanente do ensino presencial pelo ensino não presencial “[...] como forma de barateamento (e sucateamento) da educação básica e superior no futuro." (BANDEIRA; PASTI, 2020, não paginado).

Tal contexto é evidenciado pela tentativa de implementação do Homeschooling no Brasil. O Homeschooling, enquanto projeto de formação, ao mesmo tempo em que promove a precarização do ensino, fundamenta-se justamente na precarização do ensino para defender sua implementação.

Em maio do ano de 2019, o na época ${ }^{\mathrm{vi}}$, Abraham Weintraub, Ministro da Educação, defendeu o ensino em casa (ou ensino domiciliar) argumentando que a opção de escolha é dos pais:

Quem coloca os filhos no mundo tem que ter a primazia na educação. [...] Se o pai e a mãe estão educando bem os seus filhos, quem somos nós para interferir? Não é o que eu 
faria para os meus filhos, não foi o que eu fiz. Acho importante a interação [com outras crianças na escola], mas eu tenho que respeitar o direito do próximo para ter o meu respeitado. (CAMARGO, 2019, não paginado).

Em nome de um pretenso respeito à livre escolha dos pais, Weintraub defende retrocessos uma vez que a implementação do Homeschooling transfere a titularidade da garantia e oferta do direito à educação do Estado para as famílias, cabendo ao Estado, apenas um papel subsidiário, desconsiderando toda a trajetória histórica de luta pela declaração e garantia do direito à educação no Brasil.

Além do retrocesso do ponto de vista da garantia do direito à educação, o Homeschooling precariza a educação e desvaloriza a profissão docente, uma vez que os pais não possuem qualificação para ensinar. A proposta de Homeschooling, portanto, desconsidera que os professores são profissionais especializados e possuem tanto conhecimento específico quanto conhecimento pedagógico, dois aspectos distintos, porém, intrinsecamente relacionados e fundamentais para o exercício da docência.

O Homeschooling também não promove a socialização interferindo na garantia plena do direito à educação a partir da perspectiva do desenvolvimento integral. Além disso, retira da criança e do adolescente a proteção integral prevista pelo Estatuto da Criança e Adolescentes (ECA) especialmente no caso de proteção contra violência intrafamiliar. (BRASIL, 1990).

O Homeschooling está em discussão no Congresso Nacional, tendo já sido criada, em 02 de abril de 2019, a "Frente Parlamentar em Defesa do Homeschooling" e encontram-se tramitando projetos de lei ${ }^{\text {vii }}$ para a implementação do mesmo. O PL 6188/2019 de autoria de Geninho Zuliani, inclusive, prevê a educação domiciliar para "[...] educandos que se inserem na modalidade de educação especial" propondo a alteração do artigo 58 da LDBEN 9.394/96 incluindo a seguinte redação: "§ $4^{\circ}$ Verificada a inadequação ou a impossibilidade de inclusão do educando na rede regular de ensino, será admitida a educação básica domiciliar, sob a responsabilidade dos pais ou responsáveis [...]" (PL 6188, 2019, não paginado, grifo nosso) abrindo margem para a indução de práticas de caráter excludente.

A concepção conteudista da escola e da educação fortalece e naturaliza a concepção instrumental da escola e da educação. O conhecimento entendido na perspectiva instrumental limita a escola à uma finalidade prática, útil, ou seja, de uma escola que "serve para alguma coisa", de um conhecimento que "serve para alguma coisa".

No entendimento de Silva (2012) enquanto predominar o sentido exógeno da educação e da escola, ou seja, destas como um meio para outros fins, como passar no vestibular, arrumar um trabalho, ascender socialmente etc., a educação se limitará às "recompensas" que escola pode oferecer.

Esta concepção tem a ver com a lógica do capital, ou seja, é orientada pelas relações de produção focalizando a produtividade e os resultados. A concepção da educação na perspectiva conteudista e instrumental tem relação com o modelo gerencial de educação. 
O modelo gerencial desconsidera que infelizmente, o contexto de pandemia irá se agravar e que estudantes e profissionais da educação também passarão a “[...] compartilhar o trabalho com os cuidados de filhos e idosos da família.” (BANDEIRA; PASTI, 2020, não paginado).

Quando num cenário social mundial, diante da morte de milhares de vítimas da COVID-19 a preocupação das pessoas que estão relacionadas com a educação é com "o conteúdo a ser vencido", com "o fim do ano letivo", com o "diploma", com as "férias", fica claramente evidenciada a compreensão da escola a partir de sua dimensão instrumental.

As instituições de ensino, em sua maioria, teoricamente, se negam a formar a partir da lógica do mercado, mas contraditoriamente, estão operando a partir desta lógica ao localizar o fim do seu fazer na produtividade e nos resultados: no conteúdo "repassado", na "aula dada" etc.

Tal perspectiva está associada a um determinado projeto de formação claramente articulado com o capital e, portanto, a partir de uma ideologia alienante que exerce "[...] uma pressão tão imensa sobre as pessoas, que supera toda a educação.” (ADORNO, 1993, p. 143).

O capital, enquanto lógica de organização da sociedade e da educação, evidencia a alienação e barbárie ao localizar dimensões individuais como prioritárias em contextos que deveriam requerer humanização e solidariedade.

O discurso de que oferecer "educação" ainda que precária e ainda que não para todos é melhor do que não oferecer nenhuma "educação" além de não estar em consonância com os preceitos normativos que orientam a educação brasileira já que fere os preceitos para a garantia do direito à educação (para todos), dialoga justamente com a perspectiva que concebe a educação a partir de sua dimensão instrumental.

De acordo com Freitas (2020, não paginado) “[...] gestores estão num mundo que não existe mais, achando que depois da pandemia tudo volta a ter continuidade" como antes.

A preocupação com a não previsão do retorno às atividades escolares é ínfima quando se considera o contexto social mais amplo:

\footnotetext{
Os impactos da pandemia serão intensos na formação de nossos estudantes e o melhor a fazer é reconhecer esta realidade e começar a lidar com ela, ao invés de criar uma maquiagem via "ensino através de práticas não presenciais". Nossas crianças estão - entre outros problemas - sendo impactadas em muitos casos pela perda de entes queridos, desestruturação econômica da família - quando há -, perda de emprego dos pais. Querer que em meio a tudo isso a aprendizagem das crianças siga seu curso normal via práticas à distância é no mínimo uma grande ilusão, sem falar da insensibilidade. (FREITAS, 2020, não paginado).
}

Ainda que as tecnologias, a internet e o conhecimento para utilizá-la fossem acessíveis à todos (o que é uma realidade muito distante) caberia problematizar a relação ética, estética e ontológica 
estabelecida entre educação e sociedade, e sobretudo, da educação na sociedade. A defesa de que "A educação não pode parar" é tão bárbara quanta a defesa do slogan governamental de que "O Brasil não pode parar". viii

No entendimento de Krawczyk (2020, não paginado) a defesa de que "A educação não pode parar" é parte de uma narrativa oficial que:

[...] que coloca as crianças, os jovens, as famílias e os professores na obrigação de aceitar estarmos vivendo "uma nova normalidade". Em realidade trata-se de uma falsa normalidade, que obriga todos a seguir no ritmo acelerado e pragmático. É uma narrativa que reproduz e aprofunda a visão utilitarista da vida, que ressignifica o tempo subjetivo e emocional, o tempo excepcional, o tempo presente e sua relação com o lazer. É a primazia de valores e comportamentos essenciais à nova ordem capitalista. (KRAWCZYK, 2020, não paginado).

O conhecimento tomado a partir da concepção instrumental, inclusive, se constitui como fundamento para o ataque à própria produção de conhecimento, em especial, àqueles advindos das humanidades, incluindo-se a própria área da educação.

Tal afirmativa fica evidente quando em pleno contexto de pandemia a Coordenação de Aperfeiçoamento de Pessoal de Nível Superior (CAPES) expede a Portaria n. 34, de 9 de março de 2020 que realiza o corte de bolsas dos pesquisadores.

No entendimento da Sociedade Brasileira para o Progresso da Ciência (SBPC):

É paradoxal que, num momento em que o Brasil vive situação de extrema dificuldade causada pela pandemia do COVID-19, cujo enfrentamento requer exatamente o fortalecimento de nossa capacidade de produzir conhecimento científico em todas as áreas, sejam feitos cortes nas cotas de bolsas de pós-graduação. A excelência da produção científica depende criticamente da qualidade da gestão elaborada pelos órgãos responsáveis. (SBPC ${ }^{\text {ix }}, 2020$, não paginado).

A questão central a ser considerada aqui, é justamente sobre o contexto social que estamos vivendo e a forma como estamos pensando o conhecimento, a educação e a escola neste contexto. A escola tem sim um compromisso com a sociedade, que não se restringe à simples transmissão (e cobrança) de conteúdos. As desigualdades sociais no Brasil são tão constrangedoras que em meio a pandemia muitas famílias continuarão indo até as escolas para acessar os programas sociais, sobretudo, àqueles relacionado à alimentação escolar. ${ }^{x}$

As instituições de ensino podem e devem sim utilizar os recursos tecnológicos mas não a partir de uma perspectiva restrita, conteudística e instrumental. Os recursos tecnológicos possibilitam a interação entre professores e equipes gestoras para promover discussões sobre o contexto de pandemia para que possam adensar o entendimento da realidade vivida e produzir conhecimento sobre. Os recursos 
tecnológicos podem contribuir para a interação entre gestores, professores e estudantes (e família destes) seja para promover a aproximação afetiva tão necessária, especialmente para as crianças, quanto para promover a escuta de acolhimento visando identificar àqueles que podem estar em situação de vulnerabilidade e/ou necessitando de atendimento psicológico. Os recursos tecnológicos podem sim contribuir a partir de múltiplas possibilidades, inclusive, para (res)significar a educação e a escola e sua relação com sociedade.

O contexto de pandemia, portanto, exige humanização e garantia dos direitos sociais (saúde, alimentação, moradia, segurança pública, educação etc.) de modo a amenizar, em grau máximo e para todos, as possíveis consequências causadas pela pandemia.

\section{AS IMPLICAÇÕES DA NEGAÇÃO DO DIREITO À EDUCAÇÃO: POR UMA OUTRA LÓGICA ORGANIZATIVA DA VIDA EM SOCIEDADE E DA EDUCAÇÃO}

A educação no Brasil é fundada a partir da negação do direito e a partir de privilégios. O privilégio do homem sobre a mulher, do rico sobre o pobre, do colonizador sobre o colonizado restringindo-se por muitos anos à uma parcela reduzida da sociedade. (TOMASEVSKI, 2006).

Nunca antes na história do Brasil ficou tão evidente que as implicações da negação do direito à educação são complexas e interferem tanto na dimensão individual da vida das pessoas quanto na dimensão coletiva/social da vida em sociedade.

A negação do direito à educação pelo seu sentido de ausência, faz com que a educação, e consequentemente, o conhecimento (científico) não seja reconhecido. Importa, nesta perspectiva, reconhecer que há uma relação intrínseca e dialética entre a garantia do direito à educação e o reconhecimento da ciência enquanto produção de conhecimento e orientadora das práticas e vivências individuais e coletivas da/na vida em sociedade.

No contexto brasileiro, é importante considerar que somente a partir da Constituição Federal de 1988 é que a educação passa a ser reconhecida como direito público subjetivo (BRASIL, 1988) o que significou, do ponto de vista da garantia do direito à educação, a exigibilidade do direito à educação, inclusive, prevendo-se a judicialização para seu cumprimento. A partir da CF de 1988, a educação passa se constituir como um direito-dever, cabendo ao Estado a garantia da oferta de vagas e à família a responsabilidade de matricular os filhos na escola. (BRASIL, 1988).

A CF de 1988 embora tenha apresentado avanços, restringe seu campo de atuação apenas ao ensino fundamental. A Educação Básica, como direito e como conceito (CURY, 2008) que hoje 
conhecemos só foi ser implementada no ano de 1996 a partir da exaração da Lei de Diretrizes e Bases da Educação Nacional (LDBEN). (BRASIL, 1996).

Em que pese os avanços trazidos pela LDBEN (1996) com relação ao reconhecimento da Educação Básica (constituída pelas etapas da Educação Infantil, Ensino Fundamental e Ensino Médio, e, como educação de base, gratuita, de qualidade e para todos), ela não alterou o ordenamento jurídico no que tange ao financiamento da educação, fator basilar para a garantia do direito à educação. Neste sentido, no de 1996 é implementado o Fundo de Manutenção e Desenvolvimento do Ensino Fundamental e de Valorização do Magistério $(F U N D E F)^{x i}$ que restringe seu campo de atuação para o Ensino Fundamental e somente no ano de 2007 é que ocorre a criação do Fundo de Manutenção e Desenvolvimento da Educação Básica e Valorização dos Profissionais da Educação (FUNDEB) ${ }^{\text {xii }}$ ampliando então, o financiamento também para as etapas da Educação Infantil e o Ensino Médio.

O quadro normativo com relação ao direito à educação só vai se modificar no ano de 2009 a partir da aprovação da Emenda Constitucional 59/2009, a qual dentre outros preceitos passa a prever a obrigatoriedade do ensino dos 4 aos 17 anos garantindo o maior tempo de educação obrigatória e gratuita vivida pelo Brasil. (BRASIL, 2009).

As normatizações brasileiras no que concerne ao direito à educação revelam que a educação enquanto um direito social é uma conquista histórica. Neste sentido, assentir intervenções governamentais frágeis e de cunho claramente neoliberal seria destituir de sentido todo o caminho de declaração e garantia do direito constituído até aqui:

\begin{abstract}
A pandemia demonstrou o risco da ausência de uma política pública que valorize a investigação de base e o reconhecimento social do conhecimento científico como motor de desenvolvimento social e econômico e o potencial da escola pública para que as novas gerações possam ultrapassar as crenças e os valores particulares. (KRAWCZYK, 2020, não paginado).
\end{abstract}

Os tempos de pandemia indicam do ponto de vista sociológico a necessária reinvenção das formas de viver que estabeleçam uma outra relação de sentido com a vida em sociedade que não se limitem à lógica de mercado.

No entendimento de Krenak $(2020,2020$ a) a pandemia é uma reação do planeta à destruição e argumenta que é preciso mudar a sociedade. Em suas teorizações anteriores à pandemia o autor sempre questionou as relações estabelecidas entre o homem e a natureza e a nocividade dos ditames do capital. (KRENAK, 2019).

Uma outra forma de pensar a sociedade implica também em uma nova forma de pensar a educação (formal), sobretudo, com relação à definição dos projetos educativos, já que estes definem a organização 
societária. Do ponto de vista educacional, importa, portanto, não apenas ressignificar a escola enquanto espaço epistemológico, mas como espaço político e fundamento da cidadania.

Precisamos de uma escola capaz de promover uma educação crítica e emancipadora (FREIRE, 1998, GIROUX, 1986) potente para que o indivíduo seja capaz de reconhecer e lutar contra a exploração e a opressão e assim possa tensionar a sociedade e a educação. Como coerentemente afirma Gerbase (2020) não dá pra defender o Estado Mínimo e defender a educação pública ao mesmo tempo.

A Pandemia, portanto, nos coloca diante da reflexão sobre a educação enquanto definidora da vida em sociedade e evidencia o quanto o aspecto político e de humanização e de hominização é dimensão fundante do processo formativo e da garantia do direito à educação.

\section{CONSIDERAÇÕES FINAIS}

Do estudo empreendido, é possível constatar que as iniciativas governamentais apresentadas diante do contexto de pandemia não só não avançam na garantia do direito à educação, como fazem o seu contrário, retrocedem.

As normatizações expedidas pelo Governo Federal evidenciam seus efeitos nocivos, não só pelo fato de se tratarem de normas legais impraticáveis no contexto educacional brasileiro reforçando ainda mais as desigualdades sociais já existentes no Brasil, mas também por deixar a educação exposta às políticas educacionais de cunho neoliberal que caminham na direção da precarização da educação pública e retrocedem na garantia da declaração e efetivação do direito à educação.

Tais normatizações evidenciam mais do que projetos formativos em disputa, evidenciam também uma suposta "normalidade" diante da morte de milhares de pessoas, naturalizando não só as desigualdades sociais como também a barbárie. Normalizar a barbárie é desumanizar a educação.

Neste sentido, implementação do ensino remoto emergencial no contexto da pandemia (COVID 19) nos coloca diante da necessidade de produzir conhecimento e de discutir crítica e profundamente em todos os espaços epistemológicos sobre o contexto que estamos vivendo e sobre os desdobramentos nas formas de pensar (e garantir) o direito à educação no Brasil.

O contexto de Pandemia, mais do que nunca, nos coloca diante do desafio de (res)significar a vida em sociedade, a educação e a escola enquanto espaço epistemológico e de redução das desigualdades sociais. Não basta apenas pensar na garantia da declaração e implementação do direito à educação, mas sobretudo, pensar acerca das dimensões éticas, estéticas e ontológicas em torno de qual educação está se requerendo o direito. Não é possível ignorar o contexto de pandemia e a dor gerada pelas mortes causadas por ela. Educação se recupera, vidas não. 
A crise humanitária provocada pela pandemia (COVID-19) evidencia a necessária ressignificação da educação e da sociedade tendo em vista a promoção de uma educação humanizadora potente para o estabelecimento de uma outra lógica de organização societária. Uma lógica que transcenda as dimensões individuais e produtivistas e que passe a localizar a vida em sociedade.

\section{REFERÊNCIAS}

ADORNO, T. L. W. Minima moralia. Reflexões a partir da vida danificada. São Paulo: Ática, 1993.

ALFANO; B.; SOUZA, R. Coronavírus: pandemia leva 57\% dos alunos do ensino médio brasileiro a terem aulas em casa. O Globo. Publicado em: 06 abr. 2020. Disponível em:

$<$ https://oglobo.globo.com/sociedade/coronavirus-servico/coronavirus-pandemia-leva-57-dos-alunos-doensino-medio-brasileiro-terem-aulas-em-casa-1-

24353057?fbclid=IwAR3n_PWo6heQfwKd53wkUmgTTT8dk-86C5oXEmR1jduj1DwTiP_Xd1z3B9c> Acesso em: 15 abr. 2020.

ANVISA. Ferramenta Zoom é bloqueada na Anvisa. Agência nacional de vigilância sanitária. Publicado em: 06 abr. 2020. Disponível em: <http://portal.anvisa.gov.br/noticias//asset_publisher/FXrpx9qY7FbU/content/solucao-zoom-bloqueada-naanvisa/219201?fbclid=IwAR2zscAPdjyK6_t1ZMljCeJm9N5iUpY1oFy2axCoH4jk-IcobkhKdfBdTEE $>$ Acesso em: 15 abr. 2020.

AZOULAY, A. In: CARTA Capital. Coronavírus deixa metade dos estudantes do mundo sem aulas. Revista Carta Capital. Publicado em: 18 mar. 2020. Disponível em:

$<$ https://www.cartacapital.com.br/educacao/coronavirus-deixa-metade-dos-estudantes-do-mundo-semaulas/> Acesso em: 15 abr. 2020.

BANDEIRA, O.; PASTI, A. Como o ensino a distância pode agravar as desigualdades agora. Nexo Jornal Ltda. Publicado em: 03 abr. 2020. Disponível em em:<ttps://www.nexojornal.com.br/ensaio/debate/2020/Como-o-ensino-a-dist\%C3\%A2ncia-podeagravar-as-desigualdades-agora?fbclid=IwAR3KUWRmaIj8kPN_dkIp_H2CZ7MwmS5bk4rIBbJTgRVi_AMLaSDUT8Hkew> Acesso em: 15 abr. 2020.

BRASIL. Constituição da República Federativa do Brasil, de 05 de outubro de 1988. Presidência da República. Casa Civil. Subchefia para Assuntos Jurídicos. Disponível em:

<www.planalto.gov.br/ccivil_03/constituicao/constituicaocompilado.htm> Acesso em: 15 abr. 2020.

Lei n. 8.069, de 13 de julho de 1990. Dispõe sobre o Estatuto da Criança e do Adolescente e dá outras providências. Presidência da República. Casa Civil. Subchefia para Assuntos Jurídicos. Disponível em: <http://www.planalto.gov.br/ccivil_03/leis/L8069.htm> Acesso em: 15 abr. 2020.

. Lei n. 9.394, de 20 de dezembro de 1996. Estabelece as diretrizes e bases da educação nacional. Presidência da República. Casa Civil. Subchefia para Assuntos Jurídicos. Disponível em: $<$ http://www.planalto.gov.br/ccivil_03/leis/L9394.htm> Acesso em: 15 abr. 2020.

. Lei n. 9.424, de 24 de dezembro de 1996. Dispõe sobre o Fundo de Manutenção e Desenvolvimento do Ensino Fundamental e de Valorização do Magistério, na forma prevista no art. 60, 
$7^{\mathrm{o}}$, do Ato das Disposições Constitucionais Transitórias, e dá outras providências. Presidência da República. Casa Civil. Subchefia para Assuntos Jurídicos. Disponível em: $<$ http://www.planalto.gov.br/ccivil_03/LEIS/L9424compilado.htm> Acesso em: 15 abr. 2020.

. Lei n. 11.494, de 20 de junho de 2007. Regulamenta o Fundo de Manutenção e Desenvolvimento da Educação Básica e de Valorização dos Profissionais da Educação - FUNDEB, de que trata o art. 60 do Ato das Disposições Constitucionais Transitórias; altera a Lei n o 10.195, de 14 de fevereiro de 2001; revoga dispositivos das Leis n os 9.424, de 24 de dezembro de 1996, 10.880, de 9 de junho de 2004, e 10.845, de 5 de março de 2004; e dá outras providências. Presidência da República. Casa Civil. Subchefia para Assuntos Jurídicos. Disponível em: <http://www.planalto.gov.br/ccivil_03/_ato20072010/2007/lei/111494.htm> Acesso em: 15 abr. 2020.

Emenda Constitucional n. 59, de 11 de novembro de 2009. Emenda Constitucional ${ }^{0}$ 59, de 11 de novembro de 2009. Acrescenta $\S 3^{\circ}$ ao art. 76 do Ato das Disposições Constitucionais Transitórias para reduzir, anualmente, a partir do exercício de 2009, o percentual da Desvinculação das Receitas da União incidente sobre os recursos destinados à manutenção e desenvolvimento do ensino de que trata 0 art. 212 da Constituição Federal, dá nova redação aos incisos I e VII do art. 208, de forma a prever a obrigatoriedade do ensino de quatro a dezessete anos e ampliar a abrangência dos programas suplementares para todas as etapas da educação básica, e dá nova redação ao $\S 4^{\circ}$ do art. 211 e ao $\S 3^{\circ}$ do art. 212 e ao caput do art. 214, com a inserção neste dispositivo de inciso VI. Diário Oficial da União. Presidência da República. Casa Civil. Subchefia para assuntos jurídicos. Disponível em: <http://www.planalto.gov.br/ccivil_03/Constituicao/Emendas/Emc/emc59.htm> Acesso em: 15 abr. 2020.

. Diretrizes curriculares nacionais para a Educação Infantil. Ministério da Educação. Secretaria de Educação Básica. - Brasília: MEC, SEB, 2010. Disponível em:

$<$ https://ndi.ufsc.br/files/2012/02/Diretrizes-Curriculares-para-a-E-I.pdf > Acesso em: 15 abr. 2020.

. Lei n. 12.711, de 29 de agosto de 2012. Dispõe sobre o ingresso nas universidades federais e nas instituições federais de ensino técnico de nível médio e dá outras providências. Presidência da República. Casa Civil. Subchefia para assuntos jurídicos. Disponível em: $<$ http://www.planalto.gov.br/ccivil_03/_ato2011-2014/2012/lei/112711.htm> Acesso em: 15 abr. 2020.

. Diretrizes Curriculares Nacionais Gerais da Educação Básica. Ministério da Educação. Conselho Nacional da Educação. Câmara Nacional de Educação Básica. Diretoria de Currículos e Educação Integral. Secretaria de Educação Básica. Secretaria de Educação Continuada, Alfabetização, Diversidade e Inclusão. Secretaria de Educação Profissional e Tecnológica. Brasília: MEC, SEB, DICEI, 2013. Disponível em:

$<$ http://portal.mec.gov.br/index.php?option=com_docman\&view=download\&alias=15548-d-c-neducacao-basica-nova-pdf\&Itemid=30192> Acesso em: 15 abr. 2020.

. Doença pelo coronavírus 2019. Secretaria de Vigilância em Saúde. Ministério da Saúde. Publicado em: 09 abr. 2020. Semana Epidemiológica 15 (05-10/04). Disponível em: $<$ https://www.saude.gov.br/images/pdf/2020/April/09/be-covid-08-final-2.pdf> Acesso em: 15 abr. 2020.

. Portaria n. 343, de 17 de março de 2020. Dispõe sobre a substituição das aulas presenciais por aulas em meios digitais enquanto durar a situação de pandemia do Novo Coronavírus - COVID-19. Ministério da Educação. Gabinete do Ministro. Diário Oficial da União. Publicado em: 18 mar. 2020. Edição: 53, Seção: 1, Página: 39. Disponível em: <http://www.in.gov.br/en/web/dou/-/portaria-n-343-de17-de-marco-de-2020- 
248564376?fbclid=IwAR0OHMbX40APzK6WWHnsy9s97aNx54B_wpsoJeHV9GToFlj9XpnCpeBrlSI> Acesso em: 15 abr. 2020a.

. Portaria n. 345, de 19 de março de 2020. Altera a Portaria MEC n 343, de 17 de março de 2020. Ministério da Educação. Gabinete do Ministro. Diário Oficial da União. Publicado em: 19 mar. 2020. Edição: 54-D, Seção: 1, Extra, Página: 1. Disponível em: <http://www.in.gov.br/en/web/dou/-/portaria-n345-de-19-de-marco-de-2020-

248881422 inheritRedirect $=$ true\&redirect $=\% 2 \mathrm{Fweb} \% 2 \mathrm{Fguest} \% 2 \mathrm{Fsearch} \% 3 \mathrm{FqSearch} \% 3 \mathrm{DP}$ ortaria $\% 252$ 0345\%2520de $\% 252019 \% 2520 \mathrm{de} \% 2520 \mathrm{mar} \% 25 \mathrm{C} 3 \% 25 \mathrm{~A} 7 \mathrm{o} \% 2520 \mathrm{de} \% 25202020>$ Acesso em: 15 abr. $2020 \mathrm{~b}$.

. Parecer CNE/CP 5/2020. Reorganização do Calendário Escolar e da possibilidade de cômputo de atividades não presenciais para fins de cumprimento da carga horária mínima anual, em razão da Pandemia da COVID-19. Publicado em: 28 abr. 2020. Conselho Nacional de Educação. Conselho Pleno. Ministério da Educação, 2020. Disponível em:

$<$ http://portal.mec.gov.br/index.php?option=com_docman\&view=download\&alias=145011-pcp00520\&category_slug=marco-2020-pdf\&Itemid=30192> Acesso em: 28 abr. 2020c.

. Medida Provisória 934 de 1 de abril de 2020. Estabelece normas excepcionais sobre o ano letivo da educação básica e do ensino superior decorrentes das medidas para enfrentamento da situação de emergência de saúde pública de que trata a Lei ${ }^{\circ}$ 13.979, de 6 de fevereiro de 2020. Presidência da República. Secretaria-Geral. Subchefia para Assuntos Jurídicos. Publicada em: 1 abr. 2020. Disponível em: < http://www.planalto.gov.br/ccivil_03/_Ato2019-2022/2020/Mpv/mpv934.htm> Acesso em: 15 mai. 2020 .

PL 6188 de 27 de novembro de 2019. Acrescenta parágrafos ao art. 58 da Lei no 9.394, de 1996, de diretrizes e bases da educação nacional, para dispor sobre a educação domiciliar para educandos que se inserem na modalidade de educação especial. Portal Institucional da Câmara dos Deputados. Disponível em: $<$ https://www.camara.leg.br/proposicoesWeb/fichadetramitacao?idProposicao=2230887 $>$ Acesso em: 15 abr. 2020.

.PL 786/2020. Altera dispositivo na Lei no 11.947, de 16 de Junho de 1999, que dispõe sobre o atendimento da alimentação escolar e do Programa Dinheiro Direto na Escola aos alunos da educação básica; altera as Leis nos 10.880, de 9 de junho de 2004, 11.273, de 6 de fevereiro de 2006, 11.507, de 20 de julho de 2007; revoga dispositivos da Medida Provisória no 2.178-36, de 24 de agosto de 2001, e a Lei no 8.913, de 12 de julho de 1994; e dá outras providências. Portal Institucional da Câmara dos Deputados. Disponível em:<

https://www.camara.leg.br/proposicoesWeb/fichadetramitacao?idProposicao=2241627> Acesso em: 15 abr. 2020.

. Lei n. 13.987, de 7 de abril de 2020. Altera a Lei no 11.947 , de 16 de junho de 2009, para autorizar, em caráter excepcional, durante o período de suspensão das aulas em razão de situação de emergência ou calamidade pública, a distribuição de gêneros alimentícios adquiridos com recursos do Programa Nacional de Alimentação Escolar (PNAE) aos pais ou responsáveis dos estudantes das escolas públicas de educação básica. Diário Oficial da União. Publicado em: 07 abr. 2020, Edição: 67-B, Seção: 1 Extra. Página: 9. Órgão: Atos do Poder Legislativo. Disponível em: $<$ http://www.in.gov.br/en/web/dou/-/lei-n-13.987-de-7-de-abril-de-2020-251562793> Acesso em: 15 abr. 2020. 
CÂMARA DOS DEPUTADOS. Atividade Legislativa. Propostas Legislativas. Portal Institucional da Câmara dos Deputados. Disponível em: <

https://www.camara.leg.br/buscaProposicoesWeb/pesquisaSimplificada > Acesso em: 15 abr. 2020.

CAMARGO, M. Para o ministro da Educação, é direito dos pais optar por esta modalidade de ensino; Abraham Weintraub participou de audiência no Senado. Agência Brasil. Publicado em: 07 mai. 2019. Disponível em: $<$ https://ultimosegundo.ig.com.br/educacao/2019-05-08/weintraub-defende-ensinodomiciliar-em-audiencia-no-senado.html> Acesso em: 7 mai. 2020.

CENSO ESCOLAR. Censo da Educação Básica. Notas Estatísticas. Ministério da Educação - Mec. Instituto Nacional de Estudos e Pesquisas

Educacionais Anísio Teixeira - INEP. Diretoria de Estatísticas Educacionais - DEED. 2019. Disponível em: $<$ http://portal.inep.gov.br/documents/186968/0/Notas+Estat\%C3\%ADsticas+-

+ Censo+da+Educa $\%$ C3\%A7\%C3\%A3o+B\%C3\%A1 sica+2019/43bf4c5b-b478-4c5d-ae17$7 \mathrm{~d} 55$ ced4c37d?version=1.0 $>$ Acesso em: 15 abr. 2020.

CURY, R. J. A Educação Básica como Direito. Cadernos de Pesquisa, v. 38, n. 134, p. 293-303, maio/ago. 2008. Disponível em <www.scielo.br/pdf/cp/v38n134/a0238134.pdf> Acesso em: 15 abr. 2020.

CNE. Conselho Nacional de Educação esclarece principais dúvidas sobre o ensino no país durante pandemia do coronavírus. Ministério da Educação. Disponível em: $<$ http://portal.mec.gov.br/buscageral/12-noticias/acoes-programas-e-projetos-637152388/87161-conselho-nacional-de-educacaoesclarece-principais-duvidas-sobre-o-ensino-no-pais-durante-pandemia-docoronavirus?fbclid=IwAR2vtiWmkAwhHQ18JjkGbW-iXLt1eQ42WxT3ZoTbU88z63xhNsF6SOjdqSY> Acesso em: 15 abr. 2020.

GERBASE, C. Solidariedade Seletiva. Jornal Zero Hora. Publicado em: 17 mar. 2020. Disponível em: $<$ https://gauchazh.clicrbs.com.br/colunistas/carlos-gerbase/noticia/2020/03/pandemia-tem-mostrado-aface-sombria-e-hipocrita-de-algumas-pessoas-ck7vawvik054p01oais2p1705.html> Acesso em: 15 abr. 2020 .

GIROUX, H. Teoria crítica e resistência em educação. Petrópolis: Editora Vozes, 1986.

GOMES, A. M. Nota sobre a suspensão de atividades acadêmicas nas modalidades presencial e a distância. Universidade Federal de Pernambuco (UFPE). Site Institucional. Disponível em:<https://www.ufpe.br/agencia/noticias/-/asset_publisher/VQX2pzmP0mP4/content/nota-sobre-asuspensao-de-atividades-academicas-nas-modalidades-presencial-e-adistancia/40615?fbclid=IwAR22rjOmh7ln3aP7UtoJean3j1WoJd3w2x3Ioh8AT_lwJ8dw-Zt0a4fXMMM> Acesso em: 15 abr. 2020.

GUSSO, H. In: ALFANO; B. SOUZA, R. Coronavírus: pandemia leva 57\% dos alunos do ensino médio brasileiro a terem aulas em casa. O Globo. Publicado em: 06 abr. 2020. Disponível em:

$<$ https://oglobo.globo.com/sociedade/coronavirus-servico/coronavirus-pandemia-leva-57-dos-alunos-doensino-medio-brasileiro-terem-aulas-em-casa-1-

24353057?fbclid=IwAR3n_PWo6heQfwKd53wkUmgTTT8dk-86C5oXEmR1jduj1DwTiP_Xd1z3B9c> Acesso em: 15 abr. 2020. 
DUBET, F. O que é uma escola justa? Cadernos de Pesquisa, v. 34, n. 123, p. 539-555, set./dez. 2004. Disponível em: <https:/www.scielo.br/pdf/cp/v34n123/a02v34123.pdf> Acesso em: 15 abr. 2020.

FREIRE, P. Pedagogia do Oprimido. Rio de Janeiro: Paz e Terra, 1998.

FREITAS, L. C. Suspender as avaliações e unir os anos 20 e 21. Blog do Freitas. Publicado em: 2 abr. 2020. Disponível em: $<$ https://avaliacaoeducacional.com/2020/04/02/suspender-as-avaliacoes-e-unir-osanos-20-e-

21/?fbclid=IwAR19uCxvsTWUTIwAYcjMgHRR_ykNVIW9CSHO1GGL0Xr6WvNVpPjvfymvoJI> Acesso em: 15 abr. 2020.

JAKIMIU, V. C. L. Participação Estudantil no Ensino Médio: caminhos para construir uma relação de pertencimento entre os jovens e a escola. Anais do IV Seminário da Associação Nacional de Política e Administração da Educação. Universidade do Oeste de Santa Catarina. - Joaçaba, SC: Unoesc, 2016. (Série Cadernos ANPAE, v. 25). Disponível em: $<$ https://www.seminariosregionaisanpae.net.br/BibliotecaVirtual/11-Seminario/Seminario_ANPAE_Sul2016.pdf > Acesso em: 15 abr. 2020.

KRAWCZYK, A educação frente à pandemia e ao fascismo: duros combates nos aguardam. Carta Maior. Publicado em: 29 jun. 2020. Disponível em: < https://www.cartamaior.com.br/?\%2FEditoria\%2FEducacao\%2FA-educacao-frente-a-pandemia-e-aofascismo-duros-combates-nos-aguardam\%2F54\%2F47970\&fbclid=IwAR3vE3K5izHcFwUEEcbhG6kfBlgw9-O1HhoqKLSEF12TzDmTbN8sY4pMms> Acesso em: 29 jun. 2020.

KRENAK, Ailton. Ideias para adiar o fim do mundo. São Paulo: Companhia das Letras. 2019. . O amanhã não está a venda. Companhia das letras, São Paulo, 2020.

In: SOUZA, R.; MANSUR, I. Nada será como antes. Mídia Ninja. Publicado em: 10 abr. 2020. Disponível em: <https:/midianinja.org/renatasouza/nada-sera-como-antes-amanha/> Acesso em: 15 abr. 2020.

LIBÂNEO, J. C. Tendências pedagógicas na prática escolar. In: . Democratização da Escola Pública. A pedagogia crítico-social dos conteúdos. São Paulo: Loyola, 2011

LOPES, M. F. A pandemia também ameaça a proteção de dados pessoais. Nexo Jornal Ltda. Publicado em: 03 abr. 2020. Disponível em: $<$ https://www.nexojornal.com.br/ensaio/debate/2020/A-pandemiatamb\%C3\%A9m-amea\%C3\%A7a-a-prote $\% \mathrm{C} 3 \% \mathrm{~A} 7 \% \mathrm{C} 3 \% \mathrm{~A} 3 \mathrm{o}$-de-dados-

pessoais?modulo=Debate\&tema $=\operatorname{tag} \&$ edicao $=\mathrm{As} \% 20 \mathrm{crises} \% 20 \mathrm{do} \% 20$ novo $\% 20$ coronav $\% \mathrm{C} 3 \% \mathrm{ADrus} \& \mathrm{p}$ osicao $=3>$ Acesso em: 15 abr. 2020.

MINAYO, M. C. S. (org.). Pesquisa Social. Teoria, método e criatividade. 18 ed. Petrópolis: Vozes, 2001.

MEC. Ministério da Educação. Portal institucional. Disponível em: <http://portal.mec.gov.br/> Acesso em: 15 abr. 2020.

MEC. Ministério da Educação. Coronavírus. Monitoramento nas Instituições de Ensino. Disponível em: $<$ http://portal.mec.gov.br/coronavirus/> Acesso em: 29 jul. 2020a. 
PNAD. Pesquisa Nacional por Amostra de Domicílios Contínua - 2017. Disponível em: < https://www.ibge.gov.br/estatisticas/multidominio/condicoes-de-vida-desigualdade-e-pobreza/17270pnad-continua.html?edicao=21073\&t=sobre $>$ Acesso em: 15 abr. 2020.

SENADO FEDERAL. Atividade Legislativa. Proposições e Matérias. Portal Institucional do Senado Federal. Disponível em: $<$ https://www25.senado.leg.br/web/atividade/materias $>$ Acesso em: 15 abr. 2020.

SILVA, M. R. Juventude, Ensino Médio e Escola Unitária: Debatendo o Ensino Médio Politécnico. Transcrição. In: Evento Ensino Médio Inovador e Noturno. Avaliação e Relatos de Experiências. Cuiabá, MT: Ago. 2012.

SBPC. Carta à Coordenação de Aperfeiçoamento de Pessoal de Nível Superior (CAPES). Sociedade Brasileira para o Progresso da Ciência. Jornal da Ciência. Disponível em: $<$ http://www.jornaldaciencia.org.br/wp-content/uploads/2020/03/Of.-SBPC-038-ao-Presidente-daCapes.pdf > Acesso em: 15 abr. 2020.

TOMASEVSKI, K. Por que a educação não é gratuita? In: HADDAD, S.; GRACIANO, A. (Org.). $A$ educação entre os direitos humanos. Campinas, SP: Autores Associados; São Paulo, SP: Ação Educativa, 2006.

VILELA, P. R. Abraham Weintraub anuncia saída do Ministério da Educação. Agência Brasil. Publicado em: 18 jun. 2020, 16:48. Brasília. Disponível em:

$<$ https://agenciabrasil.ebc.com.br/educacao/noticia/2020-06/abraham-weintraub-anuncia-saida-doministerio-da-educacao> Acesso em: 18 de jun. 2020.

VITAL, D. Em liminar, ministro Barroso proíbe campanha "O Brasil não pode parar". Consultor Jurídico. Publicado em: 31 mar. 2020. Disponível em: <https://www.conjur.com.br/2020-mar-31/liminarbarroso-proibe-campanha-brasil-nao-parar> Acesso em: 15 abr. 2020.

YOUNG, M. Para que servem as escolas? Educ. Soc., Campinas, vol. 28, n. 101, set./dez. 2007. Disponível em: <https://www.scielo.br/pdf/es/v28n101/a0228101.pdf> Acesso em: 15 abr. 2020.

\footnotetext{
${ }^{\mathrm{i}}$ Mestre e Doutora em Educação na linha de Políticas Educacionais pela Universidade Federal do Paraná - UFPR. Membro da Red de Estudios Teóricos y Epistemológicos en Política Educativa - ReLePe. Professora nos anos iniciais do ensino fundamental da rede pública de ensino do município de União da Vitória- PR. Professora no Curso de Pedagogia da Universidade Estadual do Paraná - Campus União da Vitória. Paraná, Brasil. E-mail: vanessajakimiu@yahoo.com.br ORCID https://orcid.org/0000-0002-4177-6302

${ }^{\text {ii }}$ Maior detalhamento ver: http://portal.mec.gov.br/coronavirus/

iii 8,9 milhões de matrículas na educação infantil, 26,9 milhões de matrículas no ensino fundamental e 7,5 milhões de matrícula no ensino médio. (CENSO..., 2019).

${ }^{\text {iv }}$ No entendimento de Young (2007, p. 1294), o conhecimento poderoso "[...] não se refere a quem tem mais acesso ao conhecimento ou quem o legitima, embora ambas sejam questões importantes, mas refere-se ao que o conhecimento pode fazer, como, por exemplo, fornecer explicações confiáveis ou novas formas de se pensar a respeito do mundo."

${ }^{\mathrm{v}}$ Crianças e jovens na grande maioria pobres, negros, indígenas e quilombolas e com marcadas diferenças regionais, de raça e de gênero.
} 


\footnotetext{
vi "Em vídeo publicado nas redes sociais nesta quinta-feira [18 de junho de 2020], o economista Abraham Weintraub anunciou sua saída do cargo de ministro da Educação, que ocupava desde abril de 2019.” (VILELA, 2020, não paginado).

vii Sendo no âmbito da Câmara dos Deputados o PL 3179/2012 (Lincoln Portela), o PL 3261/2015 (Eduardo Bolsonaro), o PL 10185/2018 (Alan Rick), PL 6188/2019 (Geninho Zuliani) e o PL 2401/2019 (Poder Executivo) e no Senado Federal o PL 490/2017 (Fernando Bezerra Coelho) e o PL 28/2018 do mesmo autor. (Portais Institucionais da Câmara do Deputados e do Senado Federal, 2020, grifo nosso).

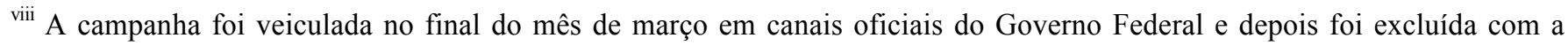
justificativa de que tratava-se de publicação em "caráter experimental". Diante desta iniciativa o "[...] ministro Luís Roberto Barroso concedeu pedido liminar para vedar a produção e circulação, por qualquer meio, de qualquer campanha que pregue que "O Brasil Não Pode Parar". A liminar ainda impede que se sugira que a população deve retornar às suas atividades plenas, ou, ainda, que expresse que a pandemia constitui evento de diminuta gravidade para a saúde e a vida da população. [...] A campanha motivou, também, uma ação levada ao STF pela OAB contra a postura do presidente Jair Bolsonaro." (VITAL, 2020, não paginado).
}

${ }^{\text {ix }}$ Em carta assinada conjuntamente com mais de 60 entidades científicas e acadêmicas e enviada ao Presidente da CAPES, Benedito Guimarães Aguiar Neto solicitando revogação da Portaria n. 34/2020.

${ }^{x}$ O PL 786/2020 (Hildo Rocha) que altera a Lei $\mathrm{n}^{\circ}$ 11.947, de 16 de junho de 2009, para autorizar, em caráter excepcional, durante o período de suspensão das aulas em razão de situação de emergência ou calamidade pública, a distribuição de gêneros alimentícios adquiridos com recursos do Programa Nacional de Alimentação Escolar (PNAE) aos pais ou responsáveis dos estudantes das escolas públicas de educação básica foi apresentado em 19 de março e foi transformado na lei ordinária n. 13. 987 em 07 de abril 2020.

${ }^{x i}$ Instituído pela lei n. 9.424, de 24 de dezembro de 1996. (BRASIL, 2006)

${ }^{\text {xii }}$ Instituído pela lei n. 11.494, de 20 de junho de 2007. (BRASIL, 2007). 